\title{
Índice geral de cursos e qualidade na educação superior: o caso das IES do Estado da Bahia
}

\author{
General index of courses and quality in higher education: \\ the case of IES in the State of Bahia
}

\author{
Ana Luiza Fernandes Mendes ${ }^{1}$ \\ ${ }^{1}$ Centro Universitário Projeção | Educação | Assessoria Acadêmica \\ Brasília |DF | Brasil. Contato: aninhafmendes@gmail.com \\ https://orcid.org/0000-0002-8256-8374
}

\author{
Norivan Lustosa Lisboa Dutra ${ }^{2}$ \\ ${ }^{2}$ Instituto Federal Brasília | Estrutural | Ensino \\ Brasília | DF | Brasil. Contato: nori.dutra@gmail.com \\ https://orcid.org/0000-0002-2533-3157
}
Resumo: Este artigo apresenta uma reflexão do processo de avaliação da Educação Superior, com destaque para o Índice Geral de Curso (ICG) nas Instituições de Ensino Superior (IES) no estado da Bahia. Integrado ao Sistema Nacional de Avaliação da Educação Superior (Sinaes), o ICG considera vários aspectos para mensurar a qualidade das IES, foi criado para ser um índice de qualidade e que se somaria a outros indicadores para impulsionar a avaliação, contudo, seus objetivos foram alterados de maneira que tem impactado nos resultados institucionais. Trata-se de uma investigação quali-quanti que se utiliza de fontes bibliográficas, documental, bem como de dados estatísticos das IES no estado da Bahia. Conclui-se que a avaliação do Ensino Superior, tem se transformado num instrumento de promoção do ranqueamento das IES, públicas e privadas, causando, com isso, sérios desafios para a gestão institucional.

Palavras-chave: Avaliação da educação superior. Qualidade. SINAES.

Abstract: This work reflects on the process of evaluation of Higher Education, with emphasis on the Course General Index (ICG) in Higher Education Institutions (IES) in the state of Bahia. Integrated to the National System of Evaluation of Higher Education (Sinaes), the ICG considers several aspects to measure the quality of IES. However, the ICG, which was to be a quality index and would be added to other indicators for the evaluation of Higher Education, has become an instrument to promote the ranking of IES, both public and private, causing, thus, serious challenges for institutional management. So, in order to reflect on such issues, a bibliographic, documentary study was carried out, with the presentation of statistical data from IES in the state of Bahia. The objective is to broaden the discussions and reflections on the theme.

Key words: High education evaluation. Quality. SINAES.

DOI: http://dx.doi.org/10.1590/S1414-407720190001000011

Recebido em: 13 de junho de 2017

Aprovado: 13 de dezembro 2018

\footnotetext{
Este é um artigo publicado em acesso aberto (Open Access) sob a licença Creative Commons Attribution Non-Commercial, que permite uso, distribuição e reprodução em qualquer meio, sem restrições desde que sem fins comerciais e que o trabalho original seja corretamente citado. https://creativecommons.org/licenses/by-nc/4.0/
} 


\section{Introdução}

A avaliação da Educação Superior tornou-se, nos últimos anos, um referencial para a gestão dos sistemas educacionais e um instrumento para potencializar a qualidade da educação. Essa prática foi preconizada pelos Estados Unidos, França, Holanda, Suécia e Inglaterra, mas ganhou repercussão também em outros países. Esses países desenvolveram projetos de avaliação institucional para maximizar as tomadas de decisões políticas e administrativas, no âmbito da educação. No Brasil, por exemplo, a avaliação ganhou forças a partir da década de 1990, no governo de Fernando Henrique Cardoso (FHC), momento em que aconteceram a reforma do Estado, a aprovação da Lei de Diretrizes e Bases da Educação (LDB - Lei 9394/96) (BRASIL, 1996), bem como a aprovação de outros documentos governamentais que estimularam a expansão das IES privadas.

A reforma do Estado significou a "descentralização para o setor público não-estatal da execução de serviços que não envolvem o exercício do poder de Estado, mas devem ser subsidiados pelo Estado, como é o caso dos serviços de educação, saúde, cultura e pesquisa científica" (BRASIL, 1995, p. 12). Com essa reforma, o Estado passa a ser o regulador das políticas públicas, em detrimento do seu papel de executor ou prestador direto de serviços.

No que se refere à avaliação das IES, a LDB de 1996 explicita no artigo 9º, inciso III e IX a responsabilidade da União quanto a necessidade de assegurar o processo nacional de avaliação das instituições de educação superior, bem como de autorizar, reconhecer, credenciar, supervisionar e avaliar os cursos das instituições de educação superior e os estabelecimentos do seu sistema de ensino.

Cabe ressaltar que a primeira experiência de avaliação institucional no Brasil aconteceu na década de 1970, nos programas de pós-graduação, sendo intensificada nos anos subsequentes. Na década de 1980 surgiu o Programa de Avaliação da Reforma Universitária (PARU) com o objetivo de avaliar os impactos da reforma universitária de 1968. Na década

de 1990 criou-se o Programa de Avaliação Institucional das Universidades Brasileiras (PAIUB), o qual teve grande adesão das IES do país, tendo em vista o caráter participativo e a autoavaliação. Contudo, com a criação do Exame Nacional de Curso (ENC) no ano de 1995, também conhecido por Provão, o PAIUB perdeu força (FONSECA; OLIVEIRA; AMARAL, 2008).

Já no governo Lula da Silva foi aprovada a Lei 10.861, de 14 de abril de 2004 (BRASIL, 2004) que criou o Sistema Nacional de Avaliação da Educação Superior (Sinaes). Este sistema é centralizado em três componentes principais: avaliação das instituições, dos 
cursos e do desempenho dos estudantes, que consideram as condições de ensino, principalmente as que são ligadas ao corpo docente, às instalações físicas, ao projeto pedagógico e ao resultado dos alunos no Exame Nacional de Desempenho dos Estudantes (Enade).

Os resultados desse processo avaliativo são divulgados pelo Ministério da Educação por meio do Censo do Educação Superior, do Conceito Preliminar de Curso (CPC) e do Índice Geral de Curso (ICG), que servirão para subsidiar o reconhecimento e recredenciamento de cursos e instituições, em todo o país, respeitando a dinâmica estruturada em ciclo trienal do Sinaes, com base nos cursos contemplados no Enade a cada ano.

O documento "Base para uma nova proposta de avaliação da educação superior" explicita que a avaliação se constitui como um "importante instrumento para identificar problemas, corrigir erros e introduzir as mudanças que signifiquem melhoria da qualidade" (BRASIL, 2003, p. 56). Observa-se, entretanto, que o Sinaes, mesmo tendo em seu projeto a articulação entre as avaliações (avaliação das instituições, dos cursos e do desempenho dos estudantes), a análise dos dados e a divulgação dos resultados acontecem de maneira fragmentada, fato que tem conduzido muitos gestores ao imediatismo em relação ao uso desses instrumentos para ações de gestão, especialmente no que tange a estratégias de planejamento e mídia. Segundo Lima, Cunha, Silva (2013, p. 107):

\footnotetext{
o discurso teórico sustenta uma avaliação democrática e participativa no paradigma da emancipação por um lado, mas por outro estamos, na prática, fortalecendo o viés regulatório, na medida em que priorizamos os comportamentos avaliativos do SINAES que trazem resultados imediatos, como notas e índices, com possibilidades de classificação e ranqueamento.
}

O ICG, por exemplo, objeto desse estudo, é um dos indicadores utilizados para avaliar a qualidade das IES, públicas e privadas. Seu resultado é divulgado anualmente pelo MEC, os quais são expressos em conceitos (insuficiente, suficiente, muito bom, excelente), com pontuação variando de um a cinco pontos.

Estudos de Bitencourt, Casarteli e Rodrigues (2009) mostram que o ICG tem servido de instrumento para o ranqueamento das instituições e também para o marketing institucional, de modo a influenciar a opinião pública, o que distorce o seu propósito, que é a avaliação da qualidade. Nessa perspectiva, entendemos ser importante a promoção de discussões, estudos e pesquisas no âmbito do Sinaes, uma vez que potencializam reflexões sobre a temática, bem como contribuem para a construção de uma visão crítica, mais coerente e mais conectada aos seus efetivos fins. 
Assim, com o propósito de refletir sobre a tais questões, em especial, sobre a qualidade da educação superior no âmbito do Sinaes, faz-se uma discussão sobre o ICG das IES no estado da Bahia.

Trata-se de um estudo descritivo, de abordagem quantitativa, amparado pela pesquisa bibliográfica e documental, incluindo levantamento de dados nos sítios eletrônicos de órgãos governamentais, tais como MEC e Instituto Nacional de Estudos e Pesquisas Educacionais Anísio Teixeira (Inep). Os dados apresentados foram tratados à luz da estatística descritiva.

A discussão foi organizada em três partes, na primeira faz-se uma discussão sobre a constituição do Sinaes e seus desafios no processo da avaliação da Educação Superior, na sequência são apresentados os dados referentes ao ICG das IES do estado da Bahia. Por fim, faz-se uma reflexão sobre os desafios da qualidade do ensino mediante o ranqueamento das IES. Estima-se que essa discussão potencialize as reflexões e promova novas inquietações, questionamentos e novas pesquisas.

\section{Sinaes: limites e possibilidades}

No entendimento de Horta Neto $(2010 ; 2014)$, avaliar é um conceito que envolve diferentes pontos de vista sobre os métodos a serem utilizados, sobre o que deve ser avaliado e, muitas vezes, é confundido com medição de resultados educacionais. Esse olhar, no entanto, limita a concepção ampliada de avaliação como um instrumento capaz de atuar sobre a realidade, a partir de diagnósticos, com análise de medidas. Uma boa avaliação precisa fazer uso de diferentes instrumentos e distintas medidas. Na percepção de Dias Sobrinho (2008, p. 2), “avaliar é uma prática relativa à garantia da qualidade, e para o Estado é um controlelegal-burocrático-formal da qualidade".

É nesse sentido que se toma o conceito de regulação como relacionado ao "objetivo de consagrar, simbolicamente, um outro estatuto a intervenção do estado na condução das políticas públicas" (BARROSO, 2005, p. 727). Ainda para o autor as referências feitas ao papel regulador do Estado servem para demarcar as propostas de modernização da administração pública, sob o modo como se ajustam às suas finalidades.

O processo de regulação compreende, não só, a produção de regras (normas, injunções, constrangimentos, etc.) que orientam o funcionamento do sistema, mas também o (re) ajustamento da diversidade de ações dos atores em função dessas mesmas regras (BARROSO, 2005, p. 733). 
No que tange à educação, a regulação é um processo complexo, dada as características inerentes ao sistema educativo da sua pluralidade de ambientes, atores, e, por conseguinte de diferentes finalidades e modalidades de regulação.

A introdução de sistemas de avaliação na educação é indispensável para o papel regulador do Estado. Controlar e avaliar, por meio de avaliações externas, dentro dos princípios do accountability é o mecanismo para uma prestação de contas à sociedade e indução à qualidade, dentro das concepções do Estado. Para Hypólito (2010, p. 1340):

\begin{abstract}
Trata-se de discursos que desempenham uma variedade de políticas em diferentes lugares, com o objetivo de criar uma noção de que as reformas são uma necessidade natural, constituem-se em parte inevitável da globalização e do mercado internacional e de uma economia cada vez mais baseada no conhecimento e que, portanto, exige mudanças radicais na forma de organizar, conceber e desenvolver a educação. Isso conduz a um deslocamento da esfera do político para a esfera do econômico, que passa a ser determinante para as definições educativas.
\end{abstract}

A regulação na educação tende a focar nos resultados da IES por intermédio dos desempenhos, medidos pelas avaliações externas. Conforme Cruz (2013), a avaliação, dentro do contexto do Sinaes, é entendida como direção e como valorização de indicadores mensuráveis, portanto, mais preocupada com o produto do que com os processos. $\mathrm{Na}$ concepção de Dias Sobrinho (2008) a avaliação e as noções de qualidade estão “ancoradas nas doutrinas e práticas neoliberais" (p. 2). Ainda segundo o autor, "não há teoria educacional que sustente que o desempenho de um estudante numa prova seja plena garantia de aprendizagem, nem de que o resultado de um conjunto de estudantes seja igual à qualidade de um curso" (p. 4). É o que vem se observando com o Sinaes.

Cabe salientar que o Sinaes foi criado com a finalidade de promover a melhoria da qualidade da educação superior. Esse sistema assegura a avaliação institucional, tanto interna quanto externa, abrangendo a análise global integrada ao ensino, à pesquisa, à extensão, à responsabilidade social, ao desempenho dos alunos, à gestão, ao corpo docente e às instalações físicas (infraestrutura). O Sinaes, portanto, orienta os gestores das IES na tomada de decisões em prol da eficácia institucional e efetividade acadêmica e social, além de subsidiar o Estado para a criação de outras políticas públicas.

O Sinaes, diferentemente de outros sistemas de avaliação no país, faz uso da autoavaliação (avaliação interna), feita pela própria IES, por meio da Comissão Própria de Avaliação (CPA). Esse tipo de avaliação ganha centralidade uma vez que consiste em 
um amplo balanço que cada instituição deve fazer para conhecer-se mais profundamente, refletir sobre suas responsabilidades, seus problemas e potencialidades, enfim, planejar e estabelecer metas para melhorar a qualidade em todas as dimensões institucionais e educativas. Nesse amplo e participativo processo de reflexão e debate público, os atores da comunidade educativa devem pôr em foco de questionamento os significados e os valores científicos, sociais, éticos, estéticos, etc. dos conteúdos, produtos, atividades, meios, fins e resultados que constituem o cotidiano da realidade concreta de uma instituição. Além de aspectos técnicos, esses processos têm uma dimensão profundamente ética e educativa, pois, contribuem para a melhora institucional e social. Por isso, a avaliação deve ser um processo global e contar com a participação comprometida de professores, estudantes e técnicos, além de representantes da comunidade externa (DIAS SOBRINHO, 2008, p. 811).

Contudo, o INEP desmontou ${ }^{1}$ uma equipe experiente nos estudos e prática avaliativa, no âmbito da educação superior, e priorizou paradigmas técnico-burocráticos. Com efeito, bloqueou a dinâmica participativa no processo avaliativo, caracterizada pela responsabilidade compartilhada da comunidade universitária. Nesse cenário, a cultura do Sinaes, que ainda não havia se consolidado, perde gradativamente, "sua riqueza teórica e sua potencialidade éticopolítica" e se reduz a índices que gera o ranqueamento, à medida e ao controle (DIAS SOBRINHO, 2008, p. 820). Nesse processo, a avaliação institucional que era central torna-se periférica e, com efeito, a importância da CPA é reduzida diante da valorização dos resultados midiáticos vinculados ao Enade, que sufocam os demais processos avaliativos que compõem o Sinaes.

Para Griboski (2015, p. 161), a avaliação, enquanto ferramenta que subsidia o acompanhamento da qualidade, requer uma série de reflexões e "precisa ser reconhecida em suas dimensões técnica, política e social, como uma possibilidade de transformação". Nesse sentido, mostra-se como necessária a um controle da expansão e a um direcionamento de qualidade.

Portanto, é indispensável analisar o Sinaes como uma política pública de educação a partir da contextualização do Estado avaliador, cujo delineamento ficou mais evidente a partir do momento em que o Estado passou a admitir a lógica de mercado. Entre as décadas de 1980 e 1990, com a adoção dos modelos de gestão privada na esfera pública, com o objetivo de gerar resultados eficazes nos sistemas produtivos, a avaliação tornou-se um pré-requisito para a implementação das políticas públicas desse Estado avaliador, expressão cunhada por Guy

\footnotetext{
1 Termo utilizado por Dias Sobrinho no texto "Qualidade, avaliação: do SINAES a índices", ao se referir à equipe que estudou e concebeu o Sinaes.
} 
Neave, em 2001, e desenvolvida por Afonso (2001), Dale (2009; 2010) e Yannoulas, Souza e Assis (2009).

Nesse cenário de governamentalidade, ${ }^{2}$ o Estado, a fim de sobreviver enquanto estrutura de poder, se utiliza de diferentes táticas para estabelecer quando determinadas ações devem competir à esfera privada ou pública. Assim, uma nova forma de gestão precisa ser fundada, a passagem do governo para governança (GUIMARÃES-IOSIF, 2012), na qual novos atores entram em cena no processo de tomada de decisões e consequentemente tem-se a inserção de determinadas políticas nas agendas para que sejam colocadas em prática.

Ressalta-se que o Sinaes tem três grandes pilares: a Avaliação Institucional, por intermédio da Autoavaliação e da Avaliação Externa; a Avaliação dos Cursos de Graduação (ACG) e a Avaliação de Desempenho dos Estudantes, por meio do Enade. Esse conjunto tem a missão de:

Identificar mérito e valor das instituições, áreas, cursos e programas, nas dimensões de ensino, pesquisa, extensão, gestão e formação; melhorar a qualidade da educação superior, orientar a expansão da oferta; e promover a responsabilidade social das IES, respeitando a identidade institucional e a autonomia (LEITE, 2011, p. 6).

Dentro da Avaliação Institucional, a autoavaliação é realizada anualmente por todas as IES do Brasil, através de suas CPA's, com a produção de um relatório de autoavaliação, no qual as ações propostas pelo Plano de Desenvolvimento Institucional (PDI) ${ }^{3}$ são articuladas com as 10 dimensões de avaliação propostas pelo Sinaes, a saber: Missão e PDI; Política para o ensino, a pesquisa, a pós-graduação e a extensão; Responsabilidade social da IES; Comunicação com a sociedade; As políticas de pessoal, as carreiras do corpo docente e técnico-administrativo; Organização de gestão da IES; Infraestrutura física; Planejamento de avaliação; Políticas de atendimento aos estudantes; Sustentabilidade financeira (BRASIL, 2004).

A avaliação externa engloba os atos de credenciamento, transformação de organização acadêmica (passar de Faculdade para Centro Universitário, por exemplo) a pedido das IES ou ocorrem trienalmente, conforme estabelecido pelo ciclo avaliativo do Sinaes ${ }^{4}$ para pedidos de

${ }^{2}$ O conceito de governamentalidade foi cunhado por Foucault (1979) no livro Microfísica do poder.

${ }^{3}$ O Plano de Desenvolvimento Institucional (PDI) é uma exigência para as instituições que deve ser atualizado quinquenalmente, e constitui um referencial para o Sinaes no preenchimento dos formulários de avaliação.

${ }^{4} \mathrm{O}$ conceito de ciclo avaliativo compreende a realização periódica de avaliação de instituições e cursos superiores, com referência nas avaliações trienais de desempenho de estudantes, as quais subsidiam, respectivamente, os atos de recredenciamento e de renovação de reconhecimento. Foi definido no artigo 33 da Portaria Normativa $n^{\circ}$ 40, de 12 de dezembro de 2007 (BRASIL.INEP, 2014). 
recredenciamento, podendo ser in loco, a depender dos conceitos da IES. Nesses atos, as 10 dimensões são articuladas com cinco eixos: Planejamento e Avaliação Institucional; Desenvolvimento Institucional; Políticas Acadêmicas; Políticas de Gestão e Infraestrutura Física. Esses eixos estão subdivididos em indicadores que representam um determinado objeto de análise, totalizando 51 indicadores (BRASIL. MEC, 2014). A avaliação externa gera o Conceito Institucional (CI) que é calculado com base na média dos conceitos estabelecidos em cada um dos cinco eixos.

A Avaliação dos Cursos de Graduação (ACG) analisa o corpo docente, a organização didático-pedagógica e a infraestrutura, e ocorre seguindo os atos regulatórios de autorização, reconhecimento e renovação de reconhecimento de cursos. De acordo com a Lei 10.861/2004, a ACG tem como objetivo identificar as condições de ensino oferecidas aos estudantes: na dimensão da organização didático-pedagógica, por exemplo, são analisados 22 (vinte e dois) indicadores que contemplam aspectos das políticas institucionais e do curso, estrutura curricular, dentre outros (BRASIL, 2004).

Já na dimensão corpo docente e tutorial são 20 (vinte) indicadores, incluindo a avaliação do coordenador de curso, do Núcleo Docente Estruturante (NDE) e da titulação, experiência e regime de trabalho do corpo docente. A infraestrutura é avaliada a partir de 21 (vinte e um) indicadores, enfatizando a estrutura dos espaços de trabalho e da biblioteca, incluindo o seu acervo. Cada indicador recebe um conceito de 1 (um) a 5 (cinco), conforme quadro abaixo e ao final de cada dimensão se tem um conceito parcial que gera por fim, a partir de uma média ponderada o Conceito de Curso (CC). Essa mesma escala é utilizada no instrumento de avaliação institucional externa.

Quadro 1 - Atribuição dos conceitos dos indicadores das dimensões e dos eixos dos Instrumentos de Avaliação do Sinaes

\begin{tabular}{|c|c|}
\hline Conceito & Descrição \\
\hline 1 & Quando os indicadores da dimensão/eixo avaliada configuram um conceito NÃO \\
& EXISTENTE. \\
\hline 2 & Quando os indicadores da dimensão avaliada/eixo configuram um conceito INSUFICIENTE. \\
\hline 3 & Quando os indicadores da dimensão avaliada/eixo configuram um conceito SUFICIENTE. \\
\hline 4 & Quando os indicadores da dimensão/eixo avaliada configuram um conceito MUITO \\
& BOM/MUITO BEM. \\
\hline 5 & Quando os indicadores da dimensão avaliada/eixo configuram um conceito EXCELENTE. \\
\hline
\end{tabular}

Fonte: BRASIL.INEP, 2015. 
De acordo com o Inep, "os cursos que obtiverem Conceito Preliminar de Curso (CPC) 4 ou 3 têm sido dispensados da avaliação in loco, uma decisão que compete à Secretaria de Regulação e Supervisão da Educação Superior (Seres) " (BRASIL. INEP, 2015a, p. 58). Os cursos com conceito 5 têm renovação automática e os que têm conceito abaixo de 3 obrigatoriamente são submetidos à avaliação in loco.

O CPC é calculado com base em três dimensões: desempenho dos estudantes, corpo docente e condições oferecidas para o desenvolvimento do processo formativo. No desempenho de estudantes se avalia os resultados do Enade e do Indicador de Diferença Entre os Desempenhos (IDD). ${ }^{5}$ Do corpo docente se avalia a titulação e o regime de trabalho. As informações sobre as condições do processo formativo são obtidas através do preenchimento do questionário do aluno no Enade, no qual ele avalia a organização didático-pedagógica, a infraestrutura e instalações físicas e o seu crescimento acadêmico e profissional (BRASIL. INEP, 2015b).

Desde a implantação do Sinaes, os instrumentos de avaliação já passaram por diversas revisões, "a partir das experiências das avaliações in loco, dos estudos sobre esse processo e com base na concepção da avaliação formativa ou contínua do Sinaes” (BRASIL. INEP, 2015a, p. 35). Os aspectos mais relevantes nessas reformulações visaram maior respeito à diversidade e à identidade dos cursos e das instituições de educação superior. De acordo com os documentos do Sinaes, os instrumentos de avaliação implementam

\begin{abstract}
um processo cíclico de avaliação, possibilita às IES revisarem as diretrizes e prioridades consolidadas no Projeto Pedagógico de Curso (PPC), utilizando o primeiro como orientação para a autoavaliação e o segundo como objeto dela, buscando novas alternativas e ações para a melhoria da gestão e da qualidade do ensino e da aprendizagem (BRASIL. INEP, 2015a, p. 39).
\end{abstract}

Nessa perspectiva, Shiroma, Campos e Garcia (2005) afirmam que a publicização ${ }^{6}$ massiva dos documentos oficiais tem por objetivo colaborar para a construção de uma "hegemonia discursiva", na medida em que ao se popularizar um conjunto de informações e ao mesmo tempo justificá-las, tem-se o caminho para torná-las legítimas. É a partir dessa legitimação que alguns conceitos são omitidos e, no caso do Sinaes, o discurso implícito

\footnotetext{
5 O cálculo do Indicador de Diferença Entre os Desempenhos Observado e Esperado (IDD) considera o "desempenho médio obtido no Enade e o desempenho médio que seria esperado pelo aluno ao final do curso" (BRASIL.INEP, 2016, p. 2).

${ }^{6}$ Publicização aqui entendida como o ato de publicar, divulgar, tornar público.
} 
prega os princípios de uma política regulatória, com vias à formatação de IES performáticas, que atendam aos padrões de mensurabilidade e de estandartização, padrões esses com vias à materialização do accountability, ao Estado mais eficaz. Essa concepção reforça o sentido do texto como um ente social, defendido por Ball (2016, p. 7), na medida em que a "política precisa ser traduzida do texto para a prática”.

O terceiro componente do tripé avaliativo do Sinaes é o Enade, que acontece trienalmente com os alunos concluintes de cada curso que esteja no ciclo avaliativo de determinado ano. O Enade tem por objetivo medir o desempenho dos alunos concluintes em relação aos conteúdos estabelecidos nas Diretrizes Curricular Nacional (DCNs) do curso e à realidade social do país e do mundo. Até 2009, o exame era feito por amostragem e aplicado aos ingressantes e aos concluintes dos cursos (BRASIL. INEP, 2015a). Em 2010, a participação deixou de ser amostral, mas em 2011 "os ingressantes deixaram de ser avaliados pelo Enade, tornando-se válidas, a título de comparação com as notas dos concluintes aquelas obtidas no Exame Nacional do Ensino Médio (ENEM)" (BRASIL. INEP, 2015a, p. 55). No gráfico 1 é possível ver o quantitativo de cursos que tiveram seus alunos avaliados entre os anos de 2004 a 2012, vejamos:

Tabela 1 - Número de cursos que tiveram seus estudantes avaliados pelo Enade, por Ciclo Avaliativo, entre 2004 e 2012

\begin{tabular}{|c|c|c|}
\hline Ciclo & Ano & Quantidade de cursos \\
\hline \multirow{3}{*}{$1^{\circ}$ ciclo } & 2004 & 2.184 \\
\hline & 2007 & 3.238 \\
\hline & 2010 & 4.281 \\
\hline \multirow{3}{*}{$2^{\circ}$ ciclo } & 2005 & 5.511 \\
\hline & 2008 & 7.329 \\
\hline & 2011 & 8.814 \\
\hline \multirow{3}{*}{$3^{\circ}$ ciclo } & 2006 & 5.701 \\
\hline & 2009 & 6.804 \\
\hline & 2012 & 7.228 \\
\hline
\end{tabular}

Fonte: BRASIL.INEP. Avaliação in loco: referenciais no âmbito do SINAES. Instituto Nacional de Estudos e Pesquisas Educacionais Anísio Teixeira. Brasília: Inep, 2015a. v. 5. p. 57.

Como é um processo cíclico, o CPC é calculado no ano seguinte da realização do Enade em cada curso. Assim, mais uma vez, a avaliação institucional gera um Conceito Institucional e, analisando-se os três pilares da Avaliação de Cursos de Graduação (ACG), tem-se o Conceito de Curso, e, juntando-se o Conceito do Enade correspondente, se constrói o CPC. A média dos três últimos CPC's disponíveis do curso mais a avaliação dos programas de pós-graduação stricto sensu da IES, realizada trienalmente pela Capes, tem-se o IGC. 
O IGC foi estabelecido como indicador de qualidade em 2007, e em 2008 passou a ser divulgado anualmente pelo Inep. Conforme Bitencourt, Casartelli e Rodrigues (2009), o IGC transformou-se em um "poderoso e polêmico instrumento de marketing institucional e de formação de opinião pública" (p. 670), podendo incorrer no risco de se tornar mais ferramenta de visibilidade publicitária, do que propriamente, de avaliação da qualidade. Uma consequência direta da divulgação do IGC é o ranqueamento entre as IES.

A tabela 2 mostra os resultados do IGC 2014 e 2015, divulgado pelo Inep. Para Lima, Cunha e Silva (2013), o Sinaes foi feito para universidades, uma vez que as 10 dimensões propostas contemplam e valorizam indicadores mais propensos a serem realizados em ambientes universitários, especialmente nas instituições que estão nas grandes metrópoles, as quais contemplam várias escolas, têm uma comunidade acadêmica de peso, ou seja, possuem docentes com alta titulação e produção científica relevantes, com amplos projetos de extensão. Muitas vezes, esses indicadores não são observados nas instituições isoladas e de pequeno porte, que são a maioria das IES no país.

Tabela 2 - IGC por organização acadêmica no Brasil, 2014 e 2015.

\begin{tabular}{ccccccc}
\hline Conceito & \multicolumn{2}{c}{ Universidades e Ifs } & Centros Universitários e & \multicolumn{2}{c}{ Faculdades } \\
& \multicolumn{2}{c}{ Cefets } & & \\
\hline & 2014 & 2015 & 2014 & 2015 & 2014 & 2015 \\
Jub Judice & 0 & 0 & 0 & 0 & 0 & 2 \\
s/c & 1 & 1 & 0 & 0 & 9 & 7 \\
$\mathbf{1}$ & 0 & 0 & 0 & 0 & 7 & 9 \\
$\mathbf{2}$ & 2 & 2 & 3 & 4 & 311 & 298 \\
$\mathbf{3}$ & 137 & 139 & 116 & 116 & 1106 & 1156 \\
$\mathbf{4}$ & 77 & 78 & 28 & 29 & 217 & 244 \\
$\mathbf{5}$ & 12 & 11 & 0 & 0 & 12 & 13 \\
Descredenciada & $1-$ & 0 & 0 & 0 & 3 & 0 \\
Total & particular & & & & & 1629 \\
\hline
\end{tabular}

Fonte: Tabela elaborada pelas autoras com base em Inep, 2016.

De todas as universidades avaliadas, no ano de 2014, duas obtiveram conceitos insatisfatórios, o que corresponde a 0,86\% e, das 1.664 faculdades avaliadas, 318 obtiveram conceitos insatisfatórios (ICG 1 e 2), configurando 19,11\% do total de IES. As 12 universidades que tiveram conceito máximo 5 (cinco), todas são da esfera públicas, sendo 08 da região sudeste, 03 do sul e 01 do centro oeste.

No ano de 2015 foram registradas 2.108 IES, sendo 10,9\% Universidades e Ifs, 7\% Centros Universitários e Cefets e $82 \%$ de faculdades. Desse total, apenas 1,13\% atingiam o 
conceito ICG máximo 5 (cinco), 66,9\% das IES alcançaram o conceito suficiente 3 (três) e 16,6\% ficaram com ICG 4 (Muito Bom).

\section{O ICG e a qualidade do ensino: o caso das IES da Bahia}

Seguindo a tendência, na Bahia, a maioria das IES ofereceram cursos como ciências sociais e humanas por serem de baixo custo de implantação. Esses cursos apresentam uma significativa oferta de vagas para uma população de cerca de 15 milhões de habitantes, concentrados em mais de $20 \%$ na capital. Por isso, ações de marketing e até ações sociais significativas na região se mostram como fatores concorrenciais importantes que requer da gestão estratégias diferenciadas de atração de alunos.

As instituições baianas, incluindo as instituições públicas, têm dificuldade de compor um corpo docente com a titulação stricto sensu, na medida em que a maioria dos programas de pós-graduação ofertados está concentrada na capital (Salvador). Outro dificultador é baixa remuneração do corpo docente que por vezes não consegue arcar com os custos de um curso de pós-graduação stricto sensu em uma instituição privada e a oferta em desses cursos em IES públicas ainda é limitada.

De acordo com Censo do Ensino Superior de 2012, do total de docentes do país, 211.394 professores estão na iniciativa privada. A maioria, 88.510 profissionais, trabalha em regime de horista, ficando na IES menos de 12 horas/aula semanais. No Nordeste estão 34.568 docentes do total nacional e são na maioria mestres, $45,89 \%$ do total. Contudo, o quantitativo de especialistas ainda é grande, 41,65\% (14.396 docentes), se comparado às regiões Sul e Sudeste do país (BRASIL. INEP, 2012).

Para melhor exemplificar a heterogeneidade da educação superior no país, foi gerada uma tabela específica com os índices do Estado da Bahia, objeto desse estudo.

Tabela 3 - IGC 2014 por organização acadêmica no estado da Bahia

\begin{tabular}{cccc}
\hline Conceito & Universidades e IF's & Centros Universitários e Cefets & Faculdades \\
\hline s/c & 0 & 0 & 1 \\
$\mathbf{1}$ & 0 & 0 & 2 \\
$\mathbf{2}$ & 0 & 0 & 24 \\
$\mathbf{3}$ & 7- 02 particulares & 2-particulares & 50 \\
$\mathbf{4}$ & 4- todas públicas & 0 & 10 \\
$\mathbf{5}$ & 0 & 0 & 1 \\
Descredenciada & 0 & 0 & 0 \\
Total & 11 & 2 & 88 \\
\hline
\end{tabular}

Fonte: Tabela elaborada pelas autoras com base em Inep, 2016. 
Os dados mostram que 29,5\%, das faculdades tiveram resultados insatisfatórios. Já entre as universidades, nenhuma atingiu a "excelência plena", e as que obtiveram conceito muito bom (4) totalizaram $36,36 \%$. Outro ponto a destacar é a porcentagem de $86,4 \%$ das IES baianas são de pequeno porte e, portanto, não tem a obrigatoriedade de desenvolver pesquisas. Além disso, a concentração da oferta de cursos stricto sensu no eixo Sul-Sudeste do país, e o baixo investimento em pesquisa nas IES baianas podem constituírem-se fatores que contribuem para configurar o IGC com menores conceitos.

Cabe salientar que 45,5\% das faculdades alcançaram o IGC considerado satisfatório (3) e apenas $1,1 \%$ atingiu o conceito máximo, no ano de 2014. Já no ano de 2015, houve melhora dos índices de uma quantidade maior de IES, vejamos na tabela 4.

Tabela 4 - IGC 2015 por organização acadêmica no estado da Bahia

\begin{tabular}{cccc}
\hline Conceito & Universidades e IF's & $\begin{array}{c}\text { Centros Universitários e } \\
\text { Cefets }\end{array}$ & Faculdades \\
\hline s/c & 0 & 0 & 1 \\
$\mathbf{1}$ & 0 & 0 & 1 \\
$\mathbf{2}$ & 0 & 0 & 19 \\
$\mathbf{3}$ & $6-02$ particular & $2-$ particular & 59 \\
$\mathbf{4}$ & $5-$ pública & 0 & 10 \\
$\mathbf{5}$ & 0 & 0 & 1 \\
Descredenciada & 0 & 0 & 0 \\
Total & 11 & 2 & 91 \\
\hline
\end{tabular}

Fonte: Tabela elaborada pelas autoras com base em Inep, 2016.

Comparando as Tabelas 3 e 4 é possível observar que não houve alteração no número de universidades e IFs. Contudo, uma IES pública subiu de conceito (de 3 para 4). Já as faculdades tiveram acréscimo de duas novas IES, em relação a 2014. Das 91 faculdades existentes em 2015, no estado da Bahia, 23\% tiveram resultado ICG insatisfatório, 65,5\% alcançaram o conceito ICG satisfatório (3), 11\% tiveram o conceito muito bom (4) e apenas $1,1 \%$ atingiu o conceito máximo (5). 


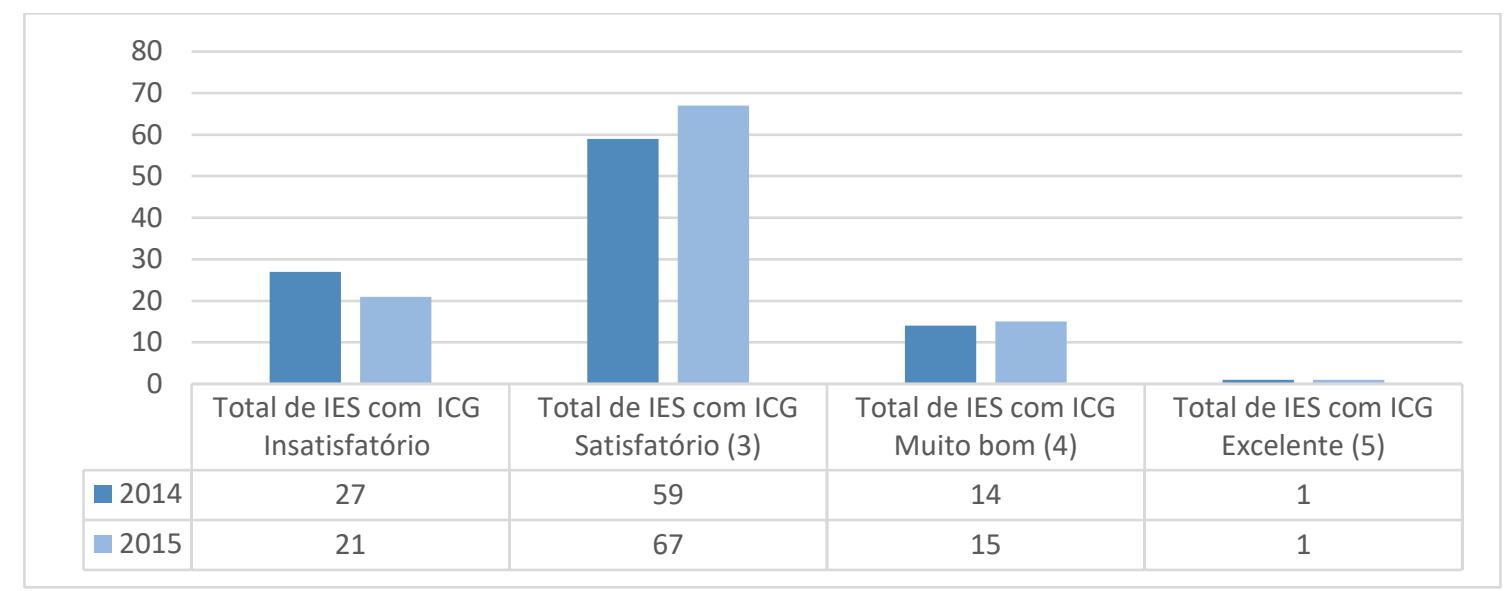

Fonte: Gráfico elaborado pelas autoras com base em Inep, 2016.

No Gráfico 1 observa-se melhora nos números de 2015 em relação ao ano de 2014 redução de seis IES que obtiveram o conceito ICG insatisfatório e aumento oito instituições que alcançaram o conceito satisfatório e uma com o ICG considerado muito bom. O número de IES com conceito excelente ficou estagnado, pois, das 13 existentes no Brasil, no ano de 2015, uma se destacou no estado da Bahia.

Esses dados sinalizam que, com base nos indicadores do Inep, a educação superior na Bahia reflete o cenário nacional, no qual, a maioria das IES se apresenta com conceito satisfatório. Cabe, com base nesse conceito, analisar se essas IES ofertam cursos de qualidade, na medida o entendimento sobre qualidade pressupõe subjetividade, já que seu conceito é polissêmico e controverso.

\section{Qualidade: performatividade e ranqueamentos}

Para Horta Neto (2010, p. 17), “conceituar qualidade não é uma tarefa simples, nem existem consensos sobre o melhor caminho a seguir". Por isso para o autor, se faz necessária a utilização de padrões de referências que permitam a sua mensuração sem perder de vista os aspectos subjetivos inerentes à qualidade, enquanto fenômeno social.

Na perspectiva da avaliação, Campo (2011) traz uma série de outras reflexões acerca de como medir qualidade: se pelos resultados dos egressos no mercado de trabalho, se pela qualidade da relação pedagógica, se pelo grau de homogeneização das condições de funcionamento das IES, seguindo os critérios dos sistemas de acreditação, pela produtividade dos docentes, pelos indicadores de pesquisas, ou se pela posição nos rankings.

Influenciado por instituições como o Banco Mundial, a OCDE e Unesco, que formulam as diretrizes políticas em nível global dentro do contexto neoliberal no qual as 
políticas estão inseridas, o Estado é levado a adotar essas diretrizes. Dessa maneira, as políticas são regulamentadas e, no caso das educacionais, são impostos padrões para se estabelecer o que é qualidade.

Tal influência é reforçada pela internacionalização da educação superior que estabeleceu critério de equiparação entre currículos internacionais e, com isso, a mobilidade acadêmica em escala global (MAGALHÃES, 2011). A Organização Mundial do Comércio (OMC) ao colocar a educação como um serviço que poderia ser gerenciado pelo mercado e não mais um bem público e dever do Estado, acirrou a concorrência entre as IES em nível mundial. A internacionalização foi facilitada pelo Processo de Bolonha, iniciado em 1988 e assinado em 19 de junho de 1999. No Acordo Geral sobre o Comércio em Serviços (AGCS) ou GATS (em inglês) assinado em 1995 se propôs a liberação da prestação dos diversos setores de serviços, inclusive da educação, em escala global, favorecendo o processo de internacionalização, que carrega consigo novos padrões de avaliação da educação em todos os seus níveis e modalidades.

Desde as tentativas de criação das universidades no país que a internacionalização, mesmo que timidamente, vem ocorrendo por meio das cooperações internacionais com o intercâmbio de docentes entre países, como com a contratação de consultores internacionais para a construção de diagnósticos sobre as IES. A partir dos anos 2000 se observou "o amadurecimento da internacionalização gestada e financiada pelas instâncias governamentais e os primeiros passos na inciativa privada" (LIMA; CONTEL, 2011, p. 160). Outro ponto a ser observado aconteceu no ano de 1995, quando o governo de Fernando Henrique Cardoso (1995 a 2002) promoveu a reforma do Estado com o objetivo de garantir maior eficiência à máquina pública.

Nesse contexto, Luiz Carlos Bresser Pereira, responsável pelo Ministério da Administração Federal e Reforma do Estado (MARE) conduziu todo o processo reformista priorizando o "fortalecimento das funções de regulação e de coordenação do Estado, particularmente no nível federal, e a progressiva descentralização vertical [...], das funções executivas no campo da prestação de serviços sociais e de infraestrutura" (BRASIL, 1995, p. 13). Em outras palavras, a reforma significou o processo de "descentralização para o setor público não-estatal da execução de serviços que não envolvem o exercício do poder de Estado, mas devem ser subsidiados pelo Estado, como é o caso dos serviços de educação, saúde, cultura e pesquisa científica" (BRASIL, 1995, p. 11-12).

Assim, a reforma do aparelho do Estado foi então estruturada em princípios gerenciais: eficiência nos serviços, por indicadores de desempenho, produtividade, baixo 
custo, descentralização, flexibilidade para atingir metas, foco nos resultados e contrato de gestão, o que implicou a transformação de muitas instituições em organizações sociais, fato legitimado pelo Programa Nacional de Publicização, criado pela Lei $n^{\circ} 9.637$ de 15 de maio de 1998.

Nesse processo, a expansão do ensino superior brasileiro foi intensificada em todo o país, com destaque para o setor privado que cresceu de maneira acelerada, enquanto as IES públicas se mantiveram praticamente estagnadas ${ }^{7}$. Vejamos a Tabela 5 a movimentação:

Tabela 5 - Número de IES e matrículas no Brasil - Setor Público e Privado

\begin{tabular}{ccccc}
\hline & & IES & & \multicolumn{2}{c}{ MATRICULAS } \\
\cline { 2 - 5 } Ano & Públicas & Privadas & Públicas & Privada \\
$\mathbf{1 9 9 6}$ & 211 & 711 & 735.427 & 1.133 .102 \\
$\mathbf{2 0 0 0}$ & 176 & 1.004 & 887.026 & 1.807 .219 \\
$\mathbf{2 0 0 4}$ & 224 & 1.789 & 1.178 .328 & 2.985 .405 \\
$\mathbf{2 0 1 0}$ & 278 & 2.099 & 1.643 .298 & 4.736 .001 \\
$\mathbf{2 0 1 4}$ & 298 & 2.070 & 1.961 .002 & 5.867 .011 \\
$\mathbf{2 0 1 5}$ & 295 & 2.069 & 1.952 .145 & 6.075 .152 \\
\hline
\end{tabular}

Fonte: Inep - Censo da Educação Superior. Elaboração própria.

Observa-se ainda, nos últimos anos, a intensificação da formação de oligopólios ${ }^{8}$ educacionais com a chegada de grupos consolidadores, até em nível internacional, refletindo na redução do número de instituições, sem reduzir o número de matrículas, ratificando a concentração de vagas no setor privado, como observado na tabela acima.

Esse processo de expansão da educação superior, reforça a tendência das IES seguirem os indicadores de desempenho e de qualidade, na performatividade e na produtividade, uma vez que existe concorrência pelo mercado educacional, agora em escala global. Esses indicadores terminam por contornar o grau de interesse do mercado por determinada IES, seja no âmbito de investimentos financeiros, por exemplo, ou da demanda por uma IES em detrimento de outras.

\footnotetext{
${ }^{7}$ Observa-se que em 2007, com o Plano de Expansão e Reestruturação das Universidades Públicas - Reuni, o número de IES cresceu, contudo em proporção ampliada para o setor privado.

${ }^{8}$ De acordo dados do Censo da Educação Superior, o mercado da educação superior privada saiu em 2009 de 1,643 milhões de "papeis" lançados na bolsa para 2.562 milhões em 2014, chegando a configurar a presença dos grupos consolidadores em 43,9\% desse mercado em 2015. Isso implica em grandes grupos educacionais com capitais abertos em bolsas de valores que buscam incorporar novas IES, com base nos princípios de eficiência e dos resultados para os acionistas.
} 
A concorrência acirrada e global, por novos candidatos ao ensino superior, faz com que a maior parte das universidades públicas ou privadas promova a educação como um produto; consequência de um amplo programa econômico (SANTOS; GUIMARÃES-IOSIF; SHULTZ, 2015). Esse modelo de educação passa a ser visto pela gestão das IES, em consonância com o preceito da performatividade na educação - o modelo que atende aos princípios da regulação, busca uma eficácia financeira pautada em padrões de qualidade.

Por esse ângulo, a performatividade pode ser vista como um "mecanismo" que traz consequências positivas para a gestão de uma IES, na medida em que se utiliza de um planejamento estratégico, com vias a alcançar de resultados positivos e que levem à sobrevivência da instituição no mercado. Contudo, a busca por esses resultados pode estar pautada na excessiva cobrança do corpo técnico e docente, na redução excessiva dos custos em detrimento da qualidade, dentre outros aspectos. Esse dualismo leva à necessidade de um entendimento da performatividade dentro da esfera da subjetividade, especialmente quando gerir uma IES torna-se cada vez mais complexo, ao se pensar nas "lógicas que impregnam esse trinômio gestão-educação superior-qualidade" (MOROSINI et al., 2016, p. 20).

No universo acadêmico, se consolida cada vez mais o conceito dos rankings. Numa simples consulta no buscador 'Google', colocando-se como palavra-chave "ranking universitário", obteve-se uma série de menções a rankings internacionais e apenas uma menção nacional. Para ranquear as IES, diferentes critérios são utilizados, desde a utilização dos índices oficiais, no caso do Brasil o IGC, como também a qualidade do curso e de seus docentes, bem como o número de pesquisas publicadas e sua reputação, a existência de programas de internacionalização, dentre outros critérios.

Os resultados da pesquisa demonstram que a maioria dos rankings é de instituições estadunidenses e avaliam as IES em escala global. O Times Higher Education World University Rankings é um dos principais rankings em nível mundial e se utiliza de indicadores como capacidade de inovação, número de citações, importância das pesquisas, para ‘qualificar' as IES. Outro que se pode destacar é o Academic Ranking of World Universities e o QS World University Rankings como outros rankings representativos e consultados por alunos no Brasil. Observa-se que apenas no ranking $Q S$ aparecem instituições brasileiras, com destaque para a Universidade de São Paulo (USP) na melhor posição, em $132^{\circ}$ lugar.

Em âmbito nacional o Ranking das Universidades do Brasil/Folha (RUF) tem se destacado como o principal ranking, e trabalha com cinco critérios, segundo o site do próprio RUF. Algumas IES, ainda segundo indicações da pesquisa on line, já utilizam a sua colocação no ranking em estratégia de mídia para captação de alunos. Ao mesmo tempo, outras IES 
divulgam justificativas sobre sua posição, a fim de esclarecer à sociedade motivos de "possíveis falhas" ou reafirmar determinadas qualidades institucionais.

Como um dos indicadores da RUF está a avaliação do mercado de trabalho, a partir de pesquisas dos principais contratantes de profissionais no mercado, que indicam a sua predileção pela origem acadêmica do pretenso profissional, através de uma pesquisa encomendada. A pesquisa acadêmica é outro indicador, e se avalia o número de trabalhos científicos publicados, proporção de publicações por docente, volume de recursos obtidos por agências financiadoras, dentre outros aspectos.

A internacionalização, seguindo tendência mundial, é mais um indicador, entretanto não pelo quantitativo de alunos em programas de estudos em outros países, como observados nos rankings internacionais. Por ele se avalia o número de citações feitas por grupo internacionais, de trabalhos da IES e publicações em coautoria internacional. Por sua vez, no indicador inovação se pontua apenas o número de patentes requeridas.

No Quadro 2 é possível observar o ranqueamento, das 5 primeiras IES da Bahia, conforme dados do Ranking Universitário Folha (RUF) 2014 e 2015.

\section{Quadro 2 - Ranking das Universidades do Estado da Bahia - 2014 e 2015}

\begin{tabular}{|l|c|l|}
\hline Ordem & Ranking 2014 & \multicolumn{1}{c|}{ Universidades } \\
\hline $\mathbf{1}$ & $14^{\circ}$ & $\underline{\text { Universidade Federal da Bahia (UFBA) }}$ \\
\hline $\mathbf{2}$ & $61^{\circ}$ & $\underline{\text { Universidade Estadual de Santa Cruz (UESC) }}$ \\
\hline $\mathbf{3}$ & $86^{\circ}$ & $\underline{\text { Universidade do Estado da Bahia (UNEB) }}$ \\
\hline $\mathbf{4}$ & $88^{\circ}$ & $\underline{\text { Universidade Estadual de Feira de Santana (UEFS) }}$ \\
\hline $\mathbf{5}$ & $89^{\circ}$ & $\underline{\text { Universidade Estadual do Sudoeste da Bahia (UESB) }}$ \\
\hline Ordem & Ranking $\mathbf{2 0 1 5}$ & \multicolumn{1}{c|}{ Universidades } \\
\hline $\mathbf{1}$ & $15^{\circ}$ & $\underline{\text { Universidade Federal da Bahia (UFBA) }}$ \\
\hline $\mathbf{2}$ & $60^{\circ}$ & $\underline{\text { Universidade Estadual de Feira de Santana (UEFS) }}$ \\
\hline $\mathbf{3}$ & $63^{\circ}$ & $\underline{\text { Universidade Estadual de Santa Cruz (UESC) }}$ \\
\hline $\mathbf{4}$ & $79^{\circ}$ & $\underline{\text { Universidade Estadual do Sudoeste da Bahia (UESB) }}$ \\
\hline $\mathbf{5}$ & $81^{\circ}$ & $\underline{\text { Universidade do Estado da Bahia (UNEB) }}$ \\
\hline
\end{tabular}

Fonte: RUF, 2014/2015. Elaboração própria.

Das 192 IES avaliadas, pela RUF em 2014, a primeira colocação ficou com Universidade de São Paulo (USP), seguida da Universidade Federal de Minas Gerais (UFMG) e Universidade Federal do Rio de Janeiro (UFRJ). No estado da Bahia a Universidade Federal da Bahia (UFBA) ficou com a melhor posição, ocupando a $14^{\circ}$ lugar, sendo seguida pela Universidade Estadual de Santa Cruz (UESC), que ficou na $61^{\circ}$ colocação. Já no ano de 2015, a mudança foi apenas na ordem das IES, pois as mesmas permaneceram entre as cinco primeiras. A exceção da UFBA que se manteve como a primeira no ranking estadual, apesar de ter subido de $14^{\circ}$ para $15^{\circ}$ no ranqueamento nacional. 
No ano de 2014 a melhor colocada entre as IES do setor privado foi a Universidade Salvador (UNIFACS) seguida da Universidade Católica do Salvador (UCSAL), ocupando, respectivamente a $104^{\circ}$ e a $140^{\circ}$ posições no ranking nacional. No ano de 2015 não foi diferente, ambas as universidades (UNIFACS e UCSAL) permanecem entre as primeiras colocações, embora com alteração na colocação, sendo $103^{\circ}$ e $164^{\circ}$, respectivamente (RUF, 2015). Já entre as faculdades, o destaque foi o Instituto Superior de Educação Ocidente que conquistou a nota máxima 5 (cinco), ficando na primeira colocação entre as IES do estado da Bahia.

Com intuito de construir escalas comparativas e definir modelos ideais de instituições, cursos, programas e métodos de ensino, na economia global, a qualidade passou a ser concebida em conformidade com padrões estabelecidos internacionalmente, mensuráveis e que podem ser enquadrados comparativamente. Diversos "atores globais institui redes que constroem, legitimam, regulam e organizam práticas que sustentam a educação superior" (SANTOS; GUIMARÃES-IOSIF; SHULTZ, 2015, p. 18).

Os desafios do que é qualidade para uma IES são tão amplos que envolvem ainda o atendimento às expectativas dos alunos, que são as mais variadas possíveis (SOUSA, 2011). Para Dias Sobrinho, “a qualidade está predominantemente associada a indicadores de desenvolvimento econômico, taxas de crescimento, números de produtos, rendimento estudantil, de captação de recursos e sustentabilidade financeira” (DIAS SOBRINHO, 2012, p. 610).

É importante destacar que as discussões sobre qualidade e educação permearam a construção do novo PNE 2014/2024 (BRASIL, 2014), no âmbito do Conselho Nacional de Educação (CNE) e nos encontros da Conferência Nacional de Educação (Conae). Entendem que a elevação da qualidade da educação superior está relacionada a aspectos ligados à sustentabilidade, criticidade do sujeito, produção de conhecimentos, que criem possibilidades de ação social e a avaliação deve ser capaz de assegurar essa qualidade (Declaração CRES, 2008 apud SPELLER; ROBL; MENEGHEL, 2012). Essas concepções de qualidade mostramse desarticuladas com os instrumentos utilizados pelo Sinaes e evidencia a sua subjetividade quando coloca o sujeito no foco da avaliação, quando na prática, a IES é o objeto avaliado, e precisa adequar-se aos critérios estabelecidos.

Assim com o vem acontecendo com outros exames de avaliação de desempenho, o Enade levou as IES a inserirem o Exame no currículo dos alunos concluintes que estão no ciclo avaliativo do Sinaes. Além disso, com o intuito de ficarem "satisfeitos" com a IES, esses 
alunos também têm atendimento diferenciado, para que posam avaliar positivamente a IES no questionário do Exame.

\section{Considerações finais}

A avaliação da educação superior é um processo complexo e isso tem levado a algumas consequências, a saber: os conceitos alcançados pela IES e divulgados pelo Sinaes tornam-se índices para o "ranqueamento" das instituições que "vendem" um bom conceito como indicativo de qualidade e, por isso, como o melhor respaldo para a escolha dos alunos.

Ao valorizar os exames de desempenho e tornar invisível a autoavaliação, que pode ser um instrumento de busca pela melhoria acadêmica, a relação ensino-aprendizagem é ignorada, uma vez que não considera a perspectiva de toda a comunidade acadêmica. Além disso, os instrumentos de avaliação não levam em conta a heterogeneidade do país, nem reconhece as desigualdades regionais, que influenciam na dinâmica da IES, como é o caso das instituições no estado da Bahia.

Tomando a avaliação como norte, a fim de atingir esses bons conceitos, os gestores das instituições buscam adequar a IES às demandas do Sinaes, como bem afirma Santos (2003, p. 2), os gestores trabalham em duas perspectivas: "o de atender às necessidades pedagógicas [...] e o de atender, ao mesmo tempo, ao padrão de qualidade”. Em outras palavras, a avaliação influencia as ações dos gestores, especialmente para controlar o processo e nortear as metas.

Essa tendência à performatividade ainda é impulsionada pelas políticas de regulação que estabelecem, pela avaliação, critérios mensuráveis de qualidade que se tornarão o 'rótulo' de cada IES. Assim, o Sinaes leva os gestores de IES privadas a entenderem qualidade como bom desempenho dos estudantes no Enade, com capacidade para atuar no mercado de trabalho, eficiência acadêmica e administrativa.

Como o termo 'qualidade' não consegue reunir consenso no campo educacional, assim como, garantir esta qualidade, ter um IGC 03 (considerado satisfatório pelo MEC), pode, por vezes, refletir falhas na formação dos egressos. O fato de estar adequado ao padrão de qualidade do Sinaes não implica necessariamente que o percurso formativo do egresso o levou a um efetivo preparo para o mercado de trabalho, como também para atuar como cidadão e ser capaz de proporcionar mudanças sociais.

Por qualidade na educação compartilha-se da visão de Guimarães-Iosif (2009), que a considera como capaz de transformar, de conscientizar e construir cidadania. Para a autora, a 
função da educação é "formar o homem consciente de seu papel no mundo e na sociedade, portanto, a prática educativa precisa levar em conta a dimensão humana" (GUIMARÃESIOSIF, 2009, p. 70).

Contudo, as pressões advindas das políticas de avaliação, da concorrência do mercado global, acabam por fazer com que as IES promovam a educação como um produto de um amplo programa econômico (SANTOS; GUIMARÃES-IOSIF; SHULTZ, 2015). Busca-se estar em consonância com os preceitos de performatividade na educação, atendendo aos princípios de regulação, com eficácia financeira e com os padrões de qualidade.

Ademais, o ideal de qualidade proposto pelo Sinaes molda o processo de ensino aprendizagem, quando as IES empenham seus esforços no atingimento de bons conceitos. Esse trabalho de adequação pode, muitas vezes, criar "qualidades" superficiais, como também direcionar as práticas da IES para um processo de melhoria contínua. Enfim, ajustes são necessários com vias a diminuir o hiato existente entre a avaliação e a qualidade na educação superior privada. As concepções sobre qualidade na educação precisam estar alinhadas à formação de um cidadão que reflita criticamente sobre diferentes cenários, que esteja apto a exerce sua profissão e que seja capaz de contribuir para o desenvolvimento da sociedade.

\section{Referências}

AFONSO, Almerindo Janela. Reforma do Estado e políticas educacionais entre a crise do Estado-Nação e a emergência da regulação supranacional. Educação e Sociedade, Campinas, v. 32, n. 75, p. 15-32, ago. 2001.

BALL, Stephen J. Uma análise de sua contribuição para a pesquisa em política educacional: depoimento [maio 2015]. Archivos analíticos de políticas educativas, Arizona-USA, v. 24, n. 24, p. 1-14, fev. 2016. Entrevista.

BARROSO, João. O Estado e a regulação das políticas públicas. Educação e Sociedade, Campinas, v. 26, n. 92, p. 725-751, especial, out. 2005.

BITENCOURT, Hélio Radke; CASARTELLI, Alam de Oliveira; RODRIGUES, Alziro César de Morais. Sobre o Índice Geral de Cursos (IGC). Avaliação, Campinas; Sorocaba, v. 14, n. 3, p. 667-682, nov. 2009. Disponível em: http://www.scielo.br/scielo.php?pid=S1414$40772009000300008 \&$ script=sci_abstract\&tlng=pt. Acesso em: 25 abr. 2017.

BRASIL. Plano diretor de reforma do aparelho do Estado. Brasília: MARE, Brasília, 1995. Disponível em:

http://www.bresserpereira.org.br/documents/mare/planodiretor/planodiretor.pdf. Acesso em: 25 abr. 2017.

BRASIL. Lei de Diretrizes e Bases da Educação (LDB). Lei no 9.394/96, de 20 de dezembro de 1996. Disponível em: http://www.planalto.gov.br/ccivil_03/leis/L9394.htm Acesso em: 20 abr. 2017. 
BRASIL. Lei no 10.861, de 14 de abril de 2004. Institui o Sistema Nacional de Avaliação da Educação Superior-SINAES e dá outras providências, 2004. Disponível em:

http://www.planalto.gov.br/ccivil_03/_Ato2004-2006/2004/Lei/L10.861.htm. Acesso em: 20 abr. 2017.

BRASIL. Lei no 13.005, de 25 de junho de 2014. Aprova o Plano Nacional de EducaçãoPNE e dá outras providências. Brasília, 2014. Disponível em:

http://www2.camara.leg.br/legin/fed/lei/2014/lei-13005-25-junho-2014-778970-

publicacaooriginal-144468-pl.html. Acesso em: 20 abr. 2017.

BRASIL. MEC. Portaria n. 92, de 31 de janeiro de 2014. Brasília, 2014. Disponível em: http://abmes.org.br/arquivos/legislacoes/Port-92-2014-01-31.pdf. Acesso em: 25 abr. 2017.

BRASIL. MEC. SINAES. Bases para uma nova proposta de avaliação da educação superior. Brasília, 2003. Disponível em: http://portal.mec.gov.br/arquivos/pdf/sinaes.pdf. Acesso em: 27 abr. 2017.

BRASIL. INEP. Censo do ensino superior ano 2012. Brasília, 2012. Disponível em: http://inep.gov.br/censo-da-educacao-superior. Acesso em: 17 fev. 2016.

BRASIL. INEP. Instrumento de Avaliação Institucional Externa. Subsidia os atos de credenciamento, recredenciamento e transformação da organização acadêmica (presencial). Brasília: Inep, 2014.

BRASIL.INEP. Conceito Preliminar de Curso (CPC). Brasília, 2014. Disponível em: http://inep.gov.br/conceito-preliminar-de-curso-cpc-. Acesso em: 28 de fev. 2017.

BRASIL.INEP. Avaliação in loco: referenciais no âmbito do SINAES. Instituto Nacional de Estudos e Pesquisas Educacionais Anísio Teixeira. Brasília: Inep, 2015a. v. 5

BRASIL.INEP. Nota técnica no 72. Cálculo do conceito preliminar de curso referente a 2013. Atualizada em maio de 2015. Brasília: Inep, 2015b.

BRASIL.INEP Resultado do Indicador de Diferença entre os Desempenhos Observados e Esperados (IDD). Brasília, 2016. Disponível em: enadeies.inep.gov.br. Acesso em: 17 fev. 2016.

CAMPO, Victor Manuel Gómez. Expansión y evaluación de la educación superior. In: CUNHA, Célio da; SOUSA, José Vieira de; SILVA, Maria Abádia da (orgs.). Políticas públicas de educação na América Latina: lições aprendidas e desafios. Campinas: Autores Associados, 2011. p. 165-192.

CRUZ, Sonia Maria de Souza Santa. Avaliação da educação superior: um estudo comparativo do Brasil e do México, 2013. Tese (Doutorado). Universidade Nove de Julho, São Paulo, 2013.

DALE, Roger. Os diferentes papéis, propósitos e resultados dos modelos nacionais e regionais de educação. Educação e Sociedade, Campinas, v. 30, n. 108, p. 867-890, out. 2009.

DALE, Roger. A sociologia e o Estado após a globalização. Educação e Sociedade, Campinas, v. 31, n. 113, p. 1099-1120, out. /dez. 2010.

DIAS SOBRINHO, José. Qualidade, avaliação: do SINAES a índices. Avaliação, Campinas; Sorocaba, v. 13, n. 3, p. 817-825, nov. 2008. Disponível em: http://www.scielo.br/pdf/aval/v13n3/11.pdf. Acesso em: 27 abr. 2017.

DIAS SOBRINHO, José. Políticas y conceptos de calidad: dilemas y retos. Avaliaçãa, Campinas; Sorocaba, v. 17, n. 3, p. 601-618, nov. 2012. Disponível em: 
http://submission.scielo.br/index.php/aval/article/view/105892/7566. Acesso em: 27 mar. 2017

FONSECA, Marilia; OLIVEIRA, João Ferreira; AMARAL, Nelson Cardoso. Avaliação, desenvolvimento institucional e qualidade do trabalho acadêmico. In: OLIVEIRA, João Ferreira; FONSECA, Marilia (orgs.). Avaliação institucional: Sinaes e práticas. Biblioteca Anpae. São Paulo: Xamã, 2008.

FOUCAULT, Michael. Microfísica do poder. Rio de Janeiro: Edições Graal, 1979.

GRIBOSKI, Cláudia Maffini. O Sinaes e a política de desenvolvimento da educação superior. In: SOUSA, José Vieira de (org.). Expansão e avaliação da educação superior brasileira: formatos, desafios e novas configurações. Belo Horizonte: Fino Traço, 2015. p. 157-176.

GUIMARÃES-IOSIF, Ranilce. Educação, pobreza e desigualdade no Brasil: impedimento para a cidadania global emancipada. Brasília: Editora Liber Livro, 2009.

GUIMARÃES-IOSIF, Ranilce. Estado, governança e política educacional: por que os educadores precisam discutir essa relação? In: KASSAR, M. C. M.; SILVA, F. C. T. (org.).

Educação e pesquisa no Centro-Oeste: políticas públicas e desafios na formação humana. Campo Grande: UFMS, 2012. p. 49-66

HYPÓLITO, Álvaro Moreira. Políticas curriculares, Estado e regulação. Educação e Sociedade, Campinas, v. 31, n. 113, p. 1337-1354, out./dez. 2010.

HORTA NETO, João Luiz. Avaliação externa de escolas e sistemas: questões presentes no debate sobre o tema. Revista Brasileira de Estudos Pedagógicos, Recife, v. 91, n. 227, p. 84-144, jan./abr. 2010.

HORTA NETO, João Luiz. Os efeitos das avaliações externas sobre as políticas educacionais do governo federal do Brasil. In: CUNHA, Célio; JESUS, Wellington Ferreira;

GUIMARÃES-IOSIF, Ranilce (orgs.). A educação em novas arenas: políticas, pesquisas e perspectivas. Brasília: Unesco, 2014. p. 51-78.

LEITE, Denise. Avaliação Institucional: desafios e perspectiva. In: SEMINÁRIO SIANES: avaliação perspectiva CONAES. Brasília, 10 de nov. 2011. Disponível em: http://portal.mec.gov.br/index.php?option=com_docman\&view=download\&alias=97791deniseleite-conaes\&category_slug=janeiro-2012-pdf\&Itemid=30192. Acesso em: 25 abr. 2017.

LIMA, Elizabeth G. dos Santos; CUNHA, Flavio 1. S. J; SILVA, Jaime Orro. Sistema Nacional de Avaliação da Educação Superior (Sinaes): reflexões e perspectivas. In: SOUSA, José Vieira de (org.). Educação superior: cenários, impasses e propostas. Campinas: Autores Associados, 2013.

LIMA, Manolita Correia; CONTEL, Fabio Betioli. Internacionalização da educação superior: nações ativas, nações passivas e geopolítica do conhecimento. São Paulo: Alameda, 2011.

MAGALHÃES, Justino. A convenção de Bolonha e a reforma do ensino universitário. In: ARAÚJO, José Carlos Souza (org.). A universidade iluminista (1929-2009): de Alfred Whitehead a Bologna. Brasília: Liber Livros, 2011. p. 251-263.

MOROSINI, Marília et al. A qualidade da educação superior e o complexo exercício de propor índices. Revista Brasileira de Educação, Rio de Janeiro, v. 21, n. 64, p. 13-37, jan./mar. 2016. 
NEAVE, Guy. Reconsideración del estado avaliador. In: NEAVE, Guy. Educación superior: histórica e política. Barcelona: Gedisa, 2001. p. 211-240.

RUF. Ranking das Universidades. 2014. Disponível em:

http://ruf.folha.uol.com.br/2014/lista/. Acesso em: 17 abr. 2017.

RUF. Ranking das Universidades. 2015. Disponível em:

http://ruf.folha.uol.com.br/2015/ranking-de-universidades/. Acesso em: 17 abr. 2017

SANTOS, Maria Alice. Avaliação e gestão no ensino superior: a percepção dos gestores frente as avaliações do MEC e da instituição: o caso do Uniceub. 2003. Dissertação (Mestrado) - Brasília: Universidade Católica de Brasília, 2003.

SANTOS, Aline Veiga dos; GUIMARÃES-IOSIF, Ranilce; SHULTZ, Lynette. (Des)construindo pontes: parcerias universitárias internacionais no Brasil e no Canadá. In: GUIMARÃES-IOSIF, Ranilce; ZARDO, Sinara Pollom; SANTOS, Aline Veiga dos (orgs.). Educação Superior: conjunturas, políticas e perspectivas. Brasília: Liber Livro, 2015. p. 1734.

SHIROMA, Eneida Oto; CAMPOS, Roselane Fátima; GARCIA, Rosalba Maria Cardoso. Decifrar textos para compreender a política: subsídios teórico-metodológicos para análise de documentos. Perspectiva, Florianópolis, v. 23, n. 2, p. 427-446, jul./dez. 2005.

SOUSA, Ana Maria Costa de. Gestão acadêmica atual. In: COLOMBO, Sonia Simões; RODRIGUES, Gabriel Mario (orgs.). Desafios da gestão universitária contemporânea. Porto Alegre: Editora Artmed, 2011. p. 97-110.

SPELLER, Paulo; ROBL, Fabiane; MENEGHEL, Stela Maria (orgs.). Desafios e perspectivas da educação superior brasileira para a próxima década. Brasília: Unesco/CNE/MEC, 2012.

YANNOULAS, Silvia Cristina; SOUZA, Camila Rosa Fernandes; ASSIS, Samuel Gabriel. Políticas educacionais e o estado avaliador: uma relação conflitante. Sociedade em Debate, Pelotas, v. 2, n. 15, p. 55-67, jul./dez. 2009. 